\title{
Radiation Exposure During Diagnostic and Therapeutic Angiography of Carotid-cavernous Fistula
}

\author{
A Retrospective Single Center Observational Study
}

\begin{abstract}
Marcel Opitz ${ }^{1}$ (D) - Georgios Alatzides ${ }^{1} \cdot$ Sebastian Zensen $^{1} \cdot$ Denise Bos ${ }^{1} \cdot$ Axel Wetter $^{1,2}$ - Nika Guberina ${ }^{3}$. Marvin Darkwah Oppong ${ }^{4}$ Karsten H. Wrede ${ }^{4} \cdot$ Tim Hagenacker $^{5}$ Yan Li $^{1}$ Isabel Wanke ${ }^{1,6}$ • Michael Forsting ${ }^{1}$. Cornelius Deuschl'
\end{abstract}

Received: 20 September 2021 / Accepted: 17 November 2021 / Published online: 21 December 2021

(c) The Author(s) 2021

\begin{abstract}
Purpose The aim of this study was to determine local diagnostic reference levels (DRLs) during endovascular diagnostics and therapy of carotid-cavernous fistulas (CCF).

Methods In a retrospective study design, DRLs, achievable dose (AD) and mean values were assessed for all patients with CCF undergoing diagnostic angiography (I) or embolization (II). All procedures were performed with the flat-panel angiography system Allura Xper (Philips Healthcare). Interventional procedures were differentiated according to the type of CCF and the type of procedure.

Results In total, 86 neurointerventional procedures of 48 patients with CCF were executed between February 2010 and July 2021. The following DRLs, AD and mean values could be determined: (I) DRL $215 \mathrm{~Gy} \cdot \mathrm{cm}^{2}, \mathrm{AD} 169 \mathrm{~Gy} \cdot \mathrm{cm}^{2}, \mathrm{mean}$ $165 \mathrm{~Gy} \cdot \mathrm{cm}^{2}$; (II) DRL $350 \mathrm{~Gy} \cdot \mathrm{cm}^{2}$, AD $226 \mathrm{~Gy} \cdot \mathrm{cm}^{2}$, mean $266 \mathrm{~Gy} \cdot \mathrm{cm}^{2}$. Dose levels of embolization were significantly higher compared to diagnostic angiography $(p<0.001)$. No significant dose difference was observed with respect to the type of fistula or the embolization method.

Conclusion This article reports on diagnostic and therapeutic DRLs in the management of CCF that could serve as a benchmark for the national radiation protection authorities. Differentiation by fistula type or embolization method does not seem to be useful.
\end{abstract}

Keywords Radiation exposure $\cdot$ Carotid-cavernous fistula $\cdot$ Embolization $\cdot$ Interventional neuroradiology $\cdot$ Cerebral angiography

Marcel Opitz

marcel.opitz@uk-essen.de

1 Institute of Diagnostic and Interventional Radiology and Neuroradiology, Faculty of Medicine, University Hospital Essen, Hufelandstraße 55, 45147 Essen, Germany

2 Department of Diagnostic and Interventional Radiology, Neuroradiology, Asklepios Klinikum Harburg, Hamburg, Germany
3 Department of Radiation Therapy, University Hospital Essen, West German Cancer Center, Essen, Germany

4 Department of Neurosurgery and Spine Surgery, University Hospital Essen, Essen, Germany

5 Department of Neurology and Center for Translational Neuro- and Behavioral Science (C-TNBS), University Hospital Essen, Essen, Germany

6 Department of Neuroradiology, Clinic Hirslanden, Zurich, Switzerland 


\section{Introduction}

Carotid-cavernous fistulas (CCFs) are abnormal communications between the carotid artery and its branches and the venous system of the cavernous sinus. Cerebral angiography is the gold standard for definitive diagnosis, classification and therapeutic planning [1]. Recent advances in endovascular technology have expanded the range of treatment options for CCFs and favorable long-term outcomes have been achieved [2-4]. As a result, the mainstay of treatment for CCFs consists of transarterial or transvenous embolization. Furthermore, the endovascular approach has evolved as the first-line treatment option in clinical emergencies and following failure of conservative therapy [5, 6]; however, other treatment options, such as open surgery or stereotactic radiosurgery are available as second-line or adjuvant therapeutic options $[7,8]$.

Neurointerventional procedures as diagnostic and therapeutic tools have increased significantly over the past decade. These minimally invasive fluoroscopy-guided procedures are an effective treatment option for various neurovascular diseases; however, due to the complexity of the pathologies being treated, some procedures may comprise high radiation exposure to patients as well as staff members [9-11], leading to an increased stochastic risk of developing radiation-induced cancer [12]. Several professional and regulatory organizations, such as the International Commission on Radiological Protection (ICRP), proclaim the necessity for diagnostic reference levels (DRLs) in regularly used neurointerventional procedures for quality control and benchmarking between institutions [13]. The goal is to raise awareness of dose and, in the long term, to optimize modification of equipment, techniques and imaging parameters [14-16].

Data on radiation exposure of diagnostic and therapeutic angiography in patients with CCF remain scarce. Hence, the aim of this study was to establish local DRLs at our department utilizing contemporary digital equipment.

Table 1 Classification of the study population with carotid-cavernous fistula (CCF) according to the Barrow-classification

\begin{tabular}{lll}
\hline Type & Shunt pattern & $n(\%)$ \\
\hline A & $\begin{array}{l}\text { Direct connection between the intracavernous } \\
\text { internal carotid artery and cavernous sinus }\end{array}$ & $14(29.2)$ \\
B & $\begin{array}{l}\text { Dural shunt between intracavernous branches } \\
\text { of the internal carotid and cavernous sinus }\end{array}$ & $8(16.7)$ \\
C & $\begin{array}{l}\text { Dural shunts between meningeal branches of } \\
\text { the external carotid artery and cavernous sinus }\end{array}$ & $3(6.2)$ \\
D & Combined type B + type C & $23(47.9)$ \\
\hline
\end{tabular}

Methods

\section{Patient Cohort}

This retrospective study was approved by the Ethics Commission of the Medical Faculty of the University of Duisburg-Essen (21-9944-BO) and was conducted in accordance with the principles of the Declaration of Helsinki. All procedures were performed after obtaining written informed consent. The internal angiographic database was searched with an in-house developed software for all consecutive diagnostic and therapeutic angiographies of CCF between February 2010 and July 2021. All CCFs were classified according to the Barrow classification (Table 1; [17]).

\section{Procedure}

All patients in this study cohort underwent diagnostic cerebral angiography (DCA) in-house or externally prior to embolization. The DCA was performed to confidently detect CCF, classify the fistula, and plan for possible embolization. The decision to perform endovascular intervention was based on a case by case evaluation in an interdisciplinary decision-making process between neurosurgeons and interventional neuroradiologists. At our department, the endovascular therapeutic approach for CCF depends on the type of fistula, the size of the arterial defect, and the surgeons' preferences. In most cases, a transvenous approach was preferred and embolization was performed using coils and/or liquid embolic agent (Onyx ${ }^{\circledR}$, Medtronic, Dublin, Ireland). In some cases, transarterial embolization was favored as an individual procedure or an additional balloon protection of the internal carotid artery was performed (Table 2). All angiographies were performed with the patient under general anesthesia.

Table 2 Demographic data and distribution of procedure type

\begin{tabular}{ll}
\hline Parameter & $n(\%)$ \\
\hline Number of patients & $48(100)$ \\
Male/female & $14(29) / 34(71)$ \\
Diagnostic angiographies & $26(54)$ \\
Number of embolizations & $60(100)$ \\
With Onyx & $7(12)$ \\
With coils & $23(38)$ \\
With Onyx and coils & $20(33)$ \\
Additional balloon protection of internal & $9(15)$ \\
carotid artery & \\
Frustrated & $10(17)$ \\
Transarterial & $12(20)$ \\
Transvenous & $48(80)$
\end{tabular}


Table 3 Distribution of total dose area product and fluoroscopic time of carotid-cavernous fistula as a function of procedure type

\begin{tabular}{lllllll}
\hline Type of procedure & \multicolumn{4}{l}{ Total DAP $\left(\mathrm{Gy} \cdot \mathrm{cm}^{2}\right)$} & FT (min) \\
\cline { 3 - 6 } & $n$ & 25th percentile & Median & 75th percentile & Mean & Mean \\
\hline Diagnostic & 26 & 101.17 & 168.61 & 214.68 & 164.83 & 18.67 \\
Embolization & 60 & 155.72 & 225.68 & 349.51 & 265.84 & 61.90 \\
\hline
\end{tabular}

$D A P$ dose area product, $F T$ fluoroscopic time, $n$ number of studies

\section{Biplanar Angiography System}

All procedures were performed on the Allura Xper FD20/10 system (Philips Healthcare, Eindhoven, The Netherlands) by an experienced team of neuroradiologists. As we are a university hospital, young neuroradiologists were regularly involved in the interventions in addition to a neuroradiologist with many years of angiography experience. The $\mathrm{X}$-ray unit was equipped with an automatic exposure control system. The frame rate frequently used in the pulsed fluoroscopy mode was 1 pulse/s. The focus-to-skin distance varied from 60 to $70 \mathrm{~cm}$. The Allura Xper system had one 20 -inch detector with a maximum field of view (FOV) of $48 \mathrm{~cm}$ and one 10-inch detector with a maximum FOV of $25 \mathrm{~cm}$. The minimum inherent filtration (at $75 \mathrm{kV}$ ) of the $\mathrm{X}$-ray tube/collimator was $2.5 \mathrm{~mm} \mathrm{Al}$. Besides a wedge filter of $1 \mathrm{~mm}$ brass (CuZn37 R-019; $22 \mathrm{~mm} \mathrm{Al}$ equivalent at $75 \mathrm{kV})$, an additional filter $(0.9 \mathrm{~mm} \mathrm{Cu}+1.0 \mathrm{~mm} \mathrm{Al})$ was set, depending on the beam-limiting device. To test the performance and stability of the system over time, regular quality checks were performed during maintenance visits.

\section{Dose Calculation}

Radiation exposure during diagnostic and therapeutic angiography was determined as dose area product (DAP). The ICRP recommends using the term DRL for both diagnostic and therapeutic interventional procedures [13]. To achieve dose optimization in the clinical routine, DRLs are a globally accepted element for dose monitoring, usually defined as DAP in interventional settings. The DRLs represent the 75th percentile of a dose distribution of a specific radiological procedure and may indicate whether the radiation dose lies within the normal range of a dose distribution at radiological departments $[18,19]$. Achievable dose (AD) is another important parameter for dose optimization representing the median of a dose distribution [20].

\section{Statistical Analysis}

The interventions were analyzed according to the type of procedure and the type of fistula. The mean, median and 75th percentile of the DAP, as well as the mean fluoroscopy time (FT) were calculated. A $p$-value below 0.05 was considered statistically significant. Statistical analysis was per- formed using SPSS (Statistical Package for Social Sciences) v. 27.0. (IBM, Armonk, NY, USA).

\section{Results}

Between February 2010 and July 2021, 86 consecutive neurointerventional procedures were performed in 48 patients with CCF in our department. The median age of patients was 64 years (range 31-87 years). The gender distribution was clearly in favor of the female gender (34 females, 14 males). Out of 48 patients with CCF, 11 patients underwent more than 1 endovascular therapy. In 10 out of 60 procedures (16.7\%), the embolization attempt had failed (Table 2).

For all patients with CCF who underwent diagnostic angiography (I) or embolization (II), the following DRL, AD and mean values were obtained: (I) DRL $215 \mathrm{~Gy} \cdot \mathrm{cm}^{2}, \mathrm{AD}$ $169 \mathrm{~Gy} \cdot \mathrm{cm}^{2}$, mean $165 \mathrm{~Gy} \cdot \mathrm{cm}^{2}$; (II) DRL $350 \mathrm{~Gy} \cdot \mathrm{cm}^{2}, \mathrm{AD}$ $226 \mathrm{~Gy} \cdot \mathrm{cm}^{2}$, mean $266 \mathrm{~Gy} \cdot \mathrm{cm}^{2}$ (Table 3; Fig. 1).

The results of one-way ANOVA confirmed a significant dose difference between DCA and embolization in patients with CCF $(p<0.001)$. The Kruskal-Wallis-test revealed no significant dose difference regarding the type of fistula according to the Barrow-Classification $(p=0.307)$ or the embolization method $(p=0.217)$. The results of the MannWhitney $U$ test confirmed no significant dose difference between the procedures with both transarterial and transvenous access and the procedures with transarterial access only $(p=0.365)$.

Excluding the unsuccessful embolization attempts from all treatment sessions, no significant difference in DAP was observed $(p=0.232)$. Likewise, no significant difference in DAP was found regarding CCF embolization by excluding all patients who underwent more than one treatment session $(p=0.556)$. No significant FT difference was found between the type of fistula $(p=0.217)$ or the embolization method $(p=0.087)$. The mean FTs are listed in Table 3 .

\section{Discussion}

This retrospective single center study is the first to provide detailed dosimetry data for endovascular treatment of CCFs. In particular, the dedicated consideration of both Barrow grade and endovascular technique is unique. Therefore, it 
Fig. 1 Histograms of distribution of dose area product $\left(\mathrm{Gy} \cdot \mathrm{cm}^{2}\right.$ ) for embolization (upper) and diagnostic cerebral angiography (lower) in patients with CCF; blue curve highlighting distribution graph
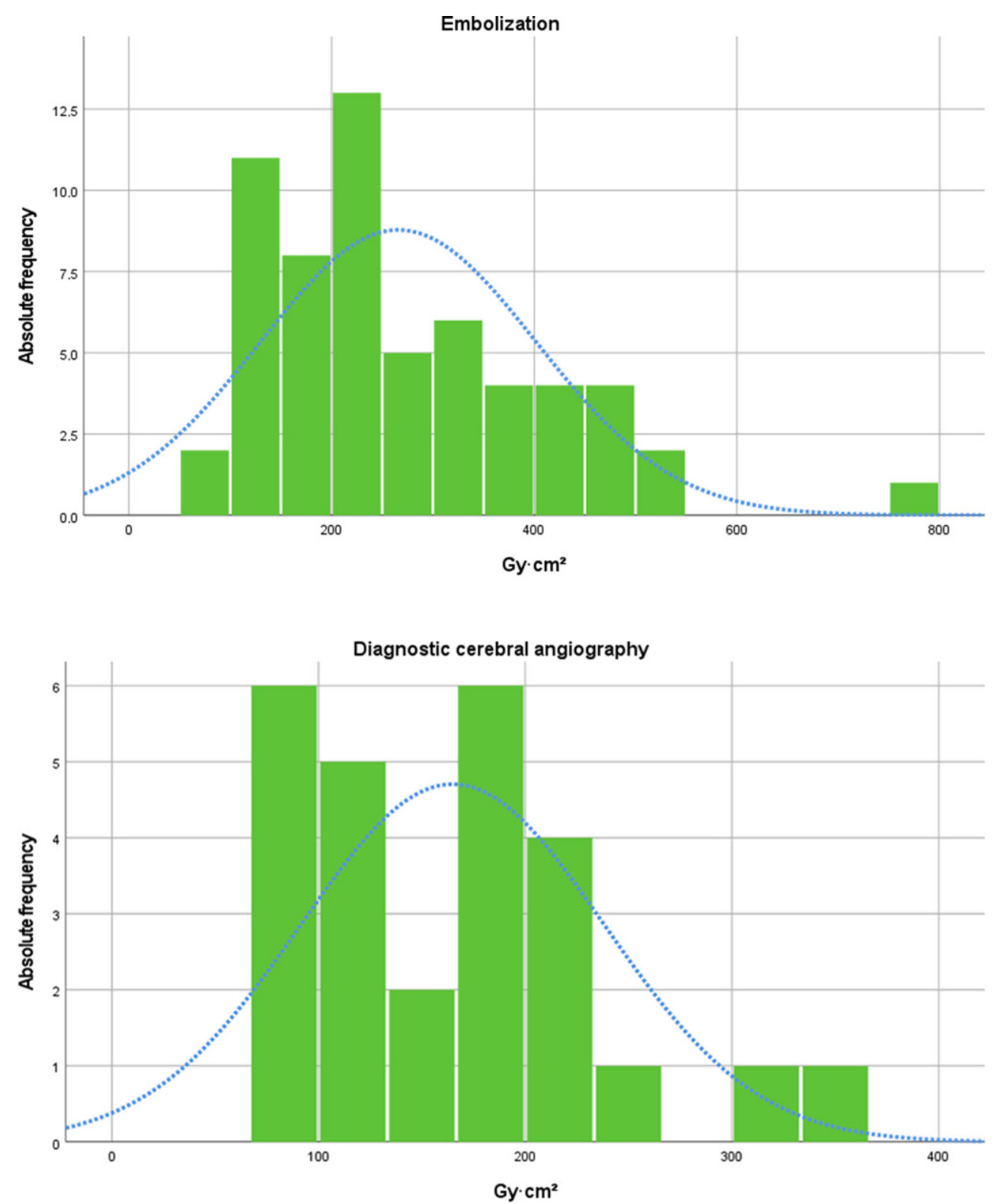

may be valuable to introduce novel DRLs in the field of interventional neuroradiology, as proposed by the European Directive 2013/59/Euratom [16].

In neuroradiology, a wide range of interventional procedures have been established over the last decade and are being used more frequently worldwide. The role of DRLs in interventional neuroradiology has increased in recent years and the guidelines for radiation protection have been updated to include interventional procedures that are regularly used in clinical routine [21-23].

Concerning interventional neuroradiology, the German Federal Office for Radiation Protection has so far only published DRLs for thrombus aspiration (DRL $180 \mathrm{~Gy} \cdot \mathrm{cm}^{2}$ ) and aneurysm coiling (DRL $\left.250 \mathrm{~Gy} \cdot \mathrm{cm}^{2}\right)$ [21]. Data on radiation exposure of other neuroradiological procedures re- main scarce and to our knowledge no data have been published for CCF embolization. The local DRLs for CCF embolization in our study $\left(350 \mathrm{~Gy} \cdot \mathrm{cm}^{2}\right)$ are substantially lower compared with published data on cranial AVM (DRL range 440-550 Gy $\cdot \mathrm{cm}^{2}$ ) [24, 25] and lateral dAVF embolization (DRL $414 \mathrm{~Gy} \cdot \mathrm{cm}^{2}$ ) [26], although comparison is difficult because of differences in anatomic location and endovascular treatment techniques.

The use of DRLs in interventional radiology is challenging because of the high individual variability of procedures within the same type of procedure. In general, it is recommended to collect radiation data of more than 50 procedures within the same type of procedure to determine DRLs for a single center [27]. As previous studies have shown, radiation exposure for interventional procedures is much more 
affected by the complexity of the procedure than by the size and weight of the patient [28]. Therefore, DRL values for interventional procedures should ideally be set according to the type and level of complexity of the procedure. In general, therapeutic procedures have been reported to yield higher doses than diagnostic procedures [29]. Consequently, diagnostic and therapeutic DRLs should be defined separately.

The main limitation of our study is the retrospective and single center design. An experienced team of neuroradiologists performed all procedures; however, young neuroradiologists are also trained at our university hospital. Thus, in terms of radiation dose, our results could indicate higher doses than can be achieved. Moreover, the obtained dose levels could differ from those obtained at other sites and angiography devices. Consequently, investigation of radiation exposure in a larger population at different sites and devices in multicenter studies is the next necessary step for the establishment of national and European DRL values.

\section{Conclusion}

The CCF embolization is a frequently used neurointerventional procedure and evolved as the leading curative therapeutic approach. Our results could serve as a benchmark for national radiation protection authorities to implement DRLs for CCF management. Differentiation by fistula type or embolization method does not seem to be useful.

Acknowledgements The authors would like to thank Dr. Irma Kollenda for constructive criticism of the manuscript.

Funding No funding was received for this study. D. Bos was supported as a Clinician Scientist within the University Medicine Essen Academy (UMEA) program, funded by the German Research Foundation (DFG; grant FU356/12-1) and the Faculty of Medicine, University of Duisburg-Essen.

Funding Open Access funding enabled and organized by Projekt DEAL.

\section{Declarations}

Conflict of interest M. Opitz, G. Alatzides, S. Zensen, D. Bos, A. Wetter, N. Guberina, M. Darkwah Oppong, K.H. Wrede, T. Hagenacker, Y. Li, I. Wanke, M. Forsting and C. Deuschl declare that they have no competing interests.

Ethical standards All procedures performed in studies involving human participants or on human tissue were in accordance with the ethical standards of the institutional and/or national research committee and with the 1975 Helsinki declaration and its later amendments or comparable ethical standards. For this retrospective study with anonymized patient data, formal consent was not required.

Open Access This article is licensed under a Creative Commons Attribution 4.0 International License, which permits use, sharing, adapta- tion, distribution and reproduction in any medium or format, as long as you give appropriate credit to the original author(s) and the source, provide a link to the Creative Commons licence, and indicate if changes were made. The images or other third party material in this article are included in the article's Creative Commons licence, unless indicated otherwise in a credit line to the material. If material is not included in the article's Creative Commons licence and your intended use is not permitted by statutory regulation or exceeds the permitted use, you will need to obtain permission directly from the copyright holder. To view a copy of this licence, visit http://creativecommons.org/licenses/by/4. $0 /$.

\section{References}

1. Henderson AD, Miller NR. Carotid-cavernous fistula: current concepts in aetiology, investigation, and management. Eye (Lond). 2018;32:164-72.

2. Alexander MD, Halbach VV, Hallam DK, Cooke DL, Ghodke BV, Dowd CF, Amans MR, Hetts SW, Higashida RT, Meyers PM. Long-Term Outcomes of Endovascular Treatment of Indirect Carotid Cavernous Fistulae: Superior Efficacy, Safety, and Durability of Transvenous Coiling Over Other Techniques. Neurosurgery. 2019;85:E94-100.

3. Al Saiegh F, Baldassari MP, Sweid A, Bilyk J, Mouchtouris N, Hafazalla K, Abendroth M, Velagapudi L, Khanna O, Chalouhi N, Sajja K, Tjoumakaris S, Gooch MR, Rosenwasser R, Jabbour P. Onyx Embolization of Carotid-Cavernous Fistulas and Its Impact on Intraocular Pressure and Recurrence: A Case Series. Oper Neurosurg (Hagerstown). 2021;20:174-82.

4. Beer-Furlan A, Joshi KC, Brahimaj B, Lopes DK. Transvenous Onyx Embolization of Carotid-Cavernous Fistulas: Mid- and Long-Term Outcomes. J Neurol Surg B Skull Base. 2021;82(Suppl 3):e278-84.

5. Korkmazer B, Kocak B, Tureci E, Islak C, Kocer N, Kizilkilic O. Endovascular treatment of carotid cavernous sinus fistula: A systematic review. World J Radiol. 2013;5:143-55.

6. Texakalidis P, Tzoumas A, Xenos D, Rivet DJ, Reavey-Cantwell J. Carotid cavernous fistula (CCF) treatment approaches: A systematic literature review and meta-analysis of transarterial and transvenous embolization for direct and indirect CCFs. Clin Neurol Neurosurg. 2021;204:106601.

7. Park SH, Park KS, Kang DH, Hwang JH, Hwang SK. Stereotactic Radiosurgery for Dural Carotid Cavernous Sinus Fistulas. World Neurosurg. 2017;106:836-43.

8. Halbach VV, Hieshima GB, Higashida RT, Reicher M. Carotid cavernous fistulae: indications for urgent treatment. AJR Am J Roentgenol. 1987;149:587-93.

9. Vano E, Fernandez JM, Sanchez RM, Martinez D, Ibor LL, Gil A, Serna-Candel C. Patient radiation dose management in the followup of potential skin injuries in neuroradiology. AJNR Am J Neuroradiol. 2013;34:277-82.

10. Tavares JB, Sacadura-Leite E, Matoso T, Neto LL, Biscoito L, Campos J, Sousa-Uva A. The importance of protection glasses during neuroangiographies: A study on radiation exposure at the lens of the primary operator. Interv Neuroradiol. 2016;22:368-71.

11. Roguin A, Goldstein J, Bar O, Goldstein JA. Brain and neck tumors among physicians performing interventional procedures. Am J Cardiol. 2013;111:1368-72.

12. Rajaraman P, Doody MM, Yu CL, Preston DL, Miller JS, Sigurdson AJ, Freedman DM, Alexander BH, Little MP, Miller DL, Linet MS. Cancer Risks in U.S. Radiologic Technologists Working With Fluoroscopically Guided Interventional Procedures, 1994-2008. AJR Am J Roentgenol. 2016;206:1101-8. Quiz 1109.

13. Vañó E, Miller DL, Martin CJ, Rehani MM, Kang K, Rosenstein M, Ortiz-López P, Mattsson S, Padovani R, Rogers A; Authors on be- 
half of ICRP. ICRP Publication 135: Diagnostic Reference Levels in Medical Imaging. Ann ICRP. 2017;46:1-144.

14. Teunen D. The European Directive on health protection of individuals against the dangers of ionising radiation in relation to medical exposures (97/43/EURATOM). J Radiol Prot. 1998;18:133-7.

15. Mountford PJ, Temperton DH. Recommendations of the International Commission on Radiological Protection (ICRP) 1990. Eur J Nucl Med. 1992;19:77-9.

16. European Council Directive 2013/59/Euratom on basic safety standards for protection against the dangers arising from exposure to ionising radiation and repealing Directives 89/618/Euratom, 90/641/Euratom, 96/29/Euratom, 97/43/Euratom and 2003/122/ Euratom. OJ of the EU. 2014;57:L13/1-73.

17. Barrow DL, Spector RH, Braun IF, Landman JA, Tindall SC, Tindall GT. Classification and treatment of spontaneous carotid-cavernous sinus fistulas. J Neurosurg. 1985;62:248-56.

18. International Atomic Energy Agency. Radiation protection and safety of radiation sources: international basic safety standards (GSR part 3). 2014. https://www-pub.iaea.org/MTCD/Publications/ PDF/Pub1578_web-57265295.pdf. Accessed 17 Sept 2021.

19. Guberina N, Forsting M, Suntharalingam S, Nassenstein K, Theysohn J, Ringelstein A, Wetter A. Radiation Dose Monitoring in the Clinical Routine. Rofo. 2017;189:356-60.

20. National Council on Radiation Protection and Measurements. Report No. 172 - Reference Levels and Achievable Doses in Medical and Dental Imaging: Recommendations for the United States. Bethesda, MD: National Council on Radiation Protection and Measurements; 2012.

21. Schegerer A, Loose R, Heuser LJ, Brix G. Diagnostic Reference Levels for Diagnostic and Interventional X-Ray Procedures in Germany: Update and Handling. Rofo. 2019;191:739-51.

22. Bundesamt für Strahlenschutz. Bekanntmachung der aktualisierten diagnostischen Referenzwerte für diagnostische und interven- tionelle Röntgenanwendungen vom 22.06.2016. 2016. https:// www.bfs.de/SharedDocs/Downloads/BfS/DE/fachinfo/ion/drwroentgen.pdf. Accessed 17 Sept 2021.

23. Bundesamt für Strahlenschutz. Bekanntmachung der aktualisierten diagnostischen Referenzwerte für interventionelle Röntgenanwendungen vom 16.08.2018. 2018. https://www.bfs.de/SharedDocs/ Downloads/BfS/DE/fachinfo/ion/drw-aktualisierung.pdf. Accessed 17 Sept 2021.

24. Miller DL, Kwon D, Bonavia GH. Reference levels for patient radiation doses in interventional radiology: proposed initial values for U.S. practice. Radiology. 2009;253:753-64.

25. Kien N, Rehel JL, Etard C, Aubert B. Dose patient en neuroradiologie interventionnelle: bilan d'une enquête multicentrique [Patient dose during interventional neuroradiology procedures: Results from a multi-center study]. J Radiol. 2011;92:1101-12.

26. Forbrig R, Stahl R, Geyer LL, Ozpeynirci Y, Liebig T, Trumm CG. Radiation Dose and Fluoroscopy Time of Endovascular Treatment in Patients with Intracranial Lateral Dural Arteriovenous Fistulae. Clin Neuroradiol. 2021;31:1149-57.

27. Vano E, Järvinen H, Kosunen A, Bly R, Malone J, Dowling A, Larkin A, Padovani R, Bosmans H, Dragusin O, Jaschke W, Torbica P, Back C, Schreiner A, Bokou C, Kottou S, Tsapaki V, Jankowski J, Papierz S, Domienik J, Werduch A, Nikodemova D, Salat D, Kepler K, Bor MD, Vassileva J, Borisova R, Pellet S, Corbett RH. Patient dose in interventional radiology: a European survey. Radiat Prot Dosimetry. 2008;129:39-45.

28. Balter S, Miller DL, Vano E, Ortiz Lopez P, Bernardi G, Cotelo E, Faulkner K, Nowotny R, Padovani R, Ramirez A. A pilot study exploring the possibility of establishing guidance levels in $\mathrm{x}$-ray directed interventional procedures. Med Phys. 2008;35:673-80.

29. Hassan AE, Amelot S. Radiation Exposure during Neurointerventional Procedures in Modern Biplane Angiographic Systems: A Single-Site Experience. Interv Neurol. 2017;6:105-16. 